\title{
Assessment of Prescribing Pattern of Drugs in the Management of Obstructive Lung Diseases and Respiratory Tract Infections
}

\section{Battu Rakesh* and Jaladi Himaja}

Department of Pharmacy Practice, Bharathi College of Pharmacy, Bharathinagara, K. M. Doddi, Mandya, Karnataka, India-571422

*Corresponding author: Battu Rakesh, Department of Pharmacy Practice, Bharathi College of Pharmacy, Bharathinagara, Mandya, Karnataka-571422 India, E-mail: rakeshjaanu143@gmail.com

\section{Received: May 05, 2017; Revised: September 29, 2017; Published: October 10, 2017}

Copyright: @2017 Rakesh B, et al. This is an open-access article distributed under the terms of the Creative Commons Attribution License, which permits unrestricted use, distribution, and reproduction in any medium, provided the original author and source are credited. The article has been previewed and authenticated by the Authors before sending the publication for print. The Journal, Editor and the Editorial Board are not entitled or liable to either justify or responsible for inaccurate and misleading data if any. It is the sole responsibility of the Author concerned.

Citation: Rakesh B, Himaja J. Assessment of Prescribing Pattern of Drugs in the Management of Obstructive Lung Diseases and Respiratory Tract Infections. Int J Pharm Pharmacol 2017; 1: 117. doi: $\underline{10.31531 / 2581-3080.1000117}$

\footnotetext{
Abstract

Background: Obstructive Diseases of Lungs such as Bronchial Asthma and Chronic Obstructive Pulmonary Disease (COPD) are public reason of ill health and death in India. The methodology to study drug use can be used as a tool to recognize whether medication use is as appropriate in management of specific subject. Chronic Respiratory Diseases (CRD) such as Bronchial Asthma and Chronic Obstructive Lung Disease (COLD) may account for a predictable encumbrance of about one hundred million individuals in India. The procedure of drug utilization review (DUR) can arrange for worthwhile means of determining whether drug use is as proper in cure of single patient.

Objectives: The foremost goals of this study are to evaluate the demographic particulars of patients with obstructive disease of lungs and to study the drug utilization pattern in obstructive lung ailment and respiratory infections in patients.

Study Design: A Cross Sectional study was carried out in the General Medicine Department in a Tertiary Care Teaching Hospital, Karnataka, using a well-designed patient data collection form.

Results: Among 102 cases of obstructive lung diseases and respiratory tract infections analysed, $65(63.36 \%)$ patients were males and $74(36.64 \%)$ were females. 49 patients (48.03\%) were found to be smokers, 41 (40.19\%) were ex-smokers, 55 (53.9\%) were alcoholics (16\%), 12 were non-smokers $(11.76 \%)$ and 29 were non-alcoholics $(28.43 \%)$ and 18 was ex-alcoholic (17.68\%). The class of drugs prescribed mostly were antibiotics (100\%), followed by anti-cholinergics (78.43\%), Short acting $\beta$ - 2 agonists (92.15\%), inhaled corticosteroids (26.47\%), Methylxanthines (69.60\%), systemic corticosteroids (32.35\%), Long acting $\beta-2$ agonist (9.80\%) and secretolytic agents (18.6\%), antihistamines (27.45\%), combination of short acting $\beta$-2 agonist + Long acting $\beta$ - 2 agonist (26.47\%).

Conclusion: Obstructive Lung diseases are more prominent in smokers when compared to nonsmokers. The pattern of drug utilization is inadequate. GOLD guidelines can be properly followed for prescribing drugs for obstructive lung diseases and can achieve total control.
} 


\section{Introduction}

Obstructive lung disease (OLD) implies a reduced capability to get air through the conducting airways and out of the lungs. This decline in airflow could also be caused by a decrease within the diameter of the airways (bronchospasm), a loss of their integrity (bronchomalacia), or a diminution in elastic recoil (emphysema) with a subsequent reduction in driving pressure [1].

The obstructive lung diseases (OLD) such as asthma and chronic obstructive pulmonary disease (COPD) are communal and are connected with substantial morbidity. Both diseases are characterized by flow of air limitation and chronic airway inflammation. Drug utilisation evaluation is a crucial part of pharmaco-epidemiological studies by which understanding of drug use according to the recommendations can be assessed [2]. Obstructive lung disease makes it tougher to respire, exclusively during increased activity or exertion.

The utmost common reasons of obstructive lung disease are:

Chronic Obstructive Pulmonary Disease (COPD)

Asthma

$>$ Bronchiectasis

Cystic Fibrosis [3].

Among these OLDs Asthma and COPD are common. Hence it became very essential to spread a thorough awareness among patients in relation to medication and disease itself. So, evaluation of drug utilization pattern in asthma and COPD will provide a powerful tool in order to find depth of awareness in patients and physician. The practice of Drug Utilization Review (DUR) can afford expedient means of determining whether drug use is as applicable in treatment of individual patients [4]. It can be used for the description of drug use pattern; early signals of irrational use of drugs; interventions to improve drug use; quality control cycle; continuous quality improvement [5].
According to World Health Organization (WHO), Drug Use Evaluation (DUE) is a system of on-going, systematic, criteria-based evaluation of drug use that will help ensure that medicines are used appropriately (at the individual patient level). DUE is the same as Drug Utilization Review (DUR) and terms are used synonymously [4]. Bad prescribing habits lead to ineffective and unsafe treatment, exacerbation or prolongation of illness, distress and harm to the patient and higher costs. Observing of medicines and drug utilization studies can recognize the glitches and deliver feedback to prescribers so as to create awareness about irrational use of drugs [6].

The goal of a DUE or MUE is to promote optimal medication therapy and ensure that drug therapy meets current standards of care. Additional objectives may include:

- Creating guidelines (criteria) for suitable drug utilization

- Evaluating the effectiveness of medication therapy

- Enhancing responsibility/accountability in the drug use process

- Controlling drug cost

- Preventing medication related problems, for example adverse drug reactions, treatment failures, over-use, under-use, incorrect doses and non-formulary medicine use

- Identifying areas in which additional data and education may be needed by healthcare providers [7].

Drug Utilization Review is increasingly used in the era of cost constraints and quality assurance [4]. It is an essential part of pharmaco-epidemiological studies; they together provide a proper understanding of usage pattern of drugs, quality and efficiency of drug use, determinants (social status of patient, therapeutic decisions of prescriber) and the outcomes of the drug use.

\section{Importance of Drug Utilization Review}

DUR programs show a significant part in helping achieved health care systems comprehend, interpret, and increase the 
prescribing, administration, and use of medications. DURs afford the managed care pharmacist the opportunity to identify trends in prescribing within groups of patients such as those with asthma, diabetes, or high blood pressure. Pharmacists can then, in collaboration with other members of the health care team, initiate action to improve drug therapy for both individual patients and covered populations. DURs serve as a means of improving the quality of patient care, enhancing therapeutic outcomes, and reducing inappropriate pharmaceutical expenditures, thus reducing overall health care costs. Hence Drug utilization studies provide useful acumens into current prescribing practices a can thus help in reforming and updating practices in clinical medicine and pharmacotherapy [8,9]. An estimated 2.2 million people worldwide die yearly because of acute respiratory infections [10]. The preferred treatment for all patients with persistent asthma is daily inhaled corticosteroid therapy as monotherapy or in combination with adjunctive therapy [11].

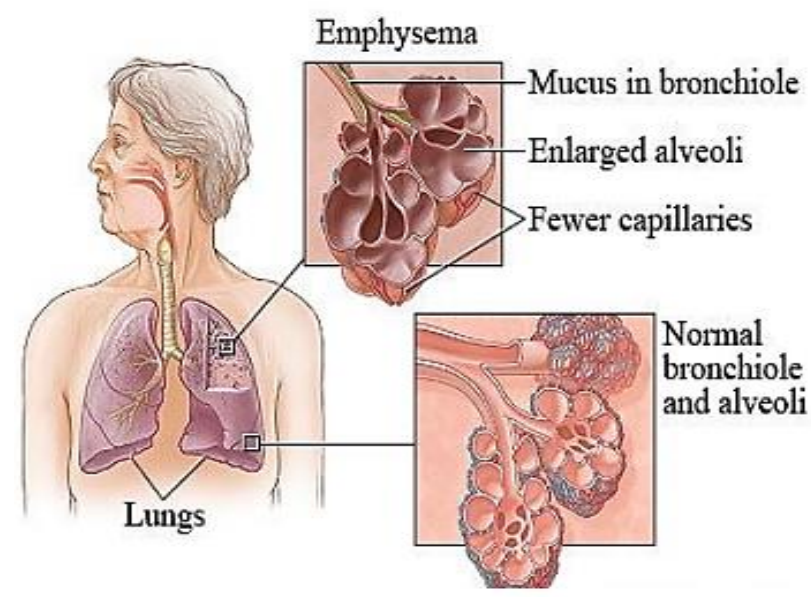

Chronic Respiratory Diseases (CRD) which are the most common cause of disease burden, both globally and in India [12].

\section{Epidemiology of Obstructive Lung Diseases}

COPD is rapidly becoming one of the world's most serious health issues. According to WHO estimates, 65 million people have moderate to severe chronic obstructive pulmonary disease (COPD). More than 3 million individuals expired of COPD in 2005, which parallels to $5 \%$ of altogether demises globally. At unique period, COPD was more common in men, but because of enlarged tobacco usage among women in high-income countries and the advanced risk of exposure to indoor air pollution (such as biomass fuel used for cooking and heating) in low-income countries, the disease now affects men and women almost equally. Estimates show that COPD becomes in 2020 the third leading cause of death worldwide [13].

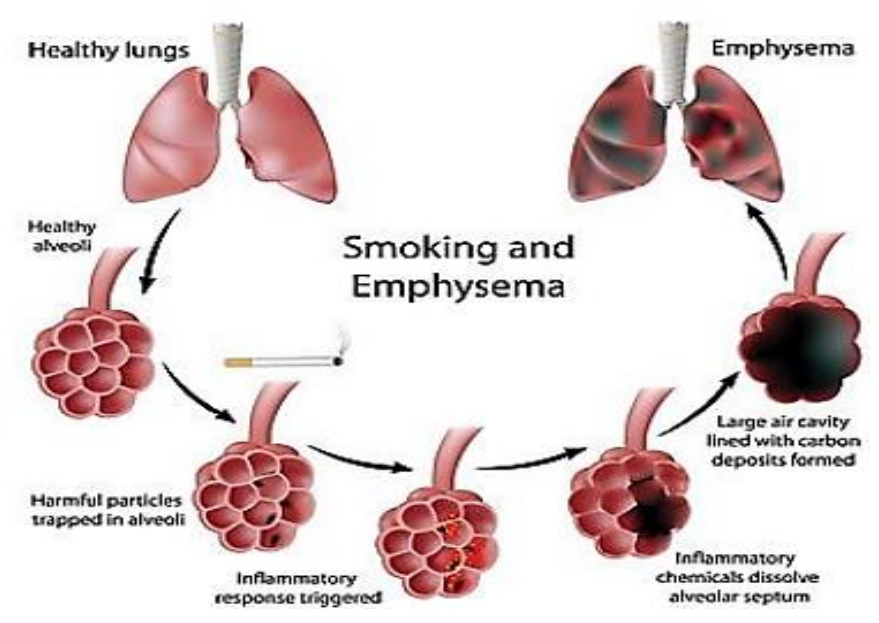

Figure 1: Bronchioles in emphysema

Chronic Obstructive Pulmonary Disease (COPD) has been a major public health problem during this century, and will remain a challenge for the future. Worldwide COPD is in spotlight, because of its high prevalence, morbidity and mortality create powerful challenges for healthcare systems [14]. The global prevalence of COPD in adults aged $>40$ years was approximately 9-10 per cent and the overall prevalence of Chronic Bronchitis in adults >35 years alone was $3.49 \%$. COPD may develop due to multiple factors and the risk factors can be genetic or environmental [15].

Global Initiative for Chronic obstructive lung disease (GOLD) defines COPD as "a common preventable and treatable disease, is characterized by persistent air flow limitation that is usually progressive and associated with an enhanced chronic inflammatory response in the airways and lung to noxious particles or gases." Exacerbations and comorbidities contribute to overall severity in 
individual patients. COPD is comprised of two disease conditions: Emphysema and Chronic Bronchitis. Emphysema (Figure 1) [16] is a disease in which the alveoli, grapelike clusters of air sacs at the end of the smallest airways (the bronchioles) are destroyed. The changes that generally occur are; the alveoli become inflamed and damaged, loss of their ability to stretch and

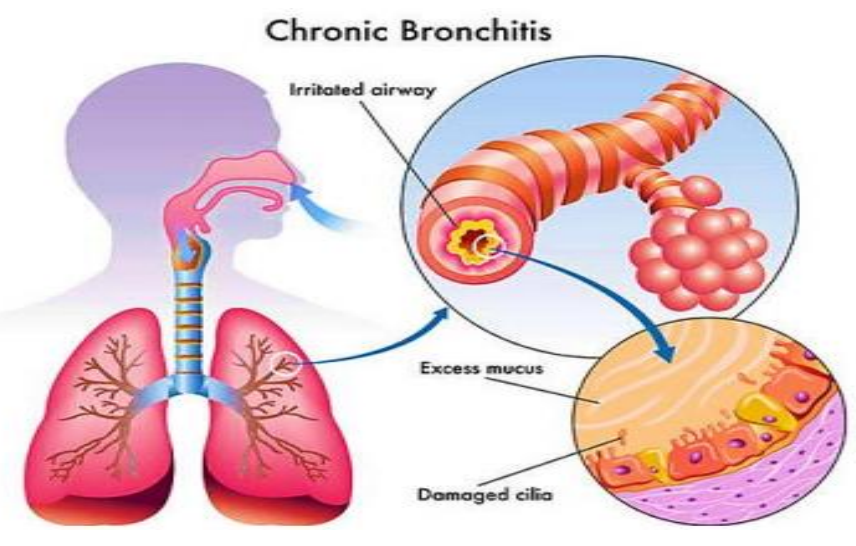

shrink (elasticity), and pockets of stagnant air (called bullae) form in the injured areas. These pockets interfere with the normal working of the lungs by narrowing the airways, trapping air, and making breathing out more difficult. But the ability to breathe in is not affected and until the late stages of the disease, oxygen and carbon dioxide levels remain normal [1].

Figure 2: Airways in chronic bronchitis

Chronic bronchitis is defined as coughing and excess mucus production that occurs for at least 3 months, during at least 2 consecutive years. In chronic bronchitis, there will be inflammation of the bronchial tubes (from smoking and air pollution), which causes the production of mucus that clogs the airways

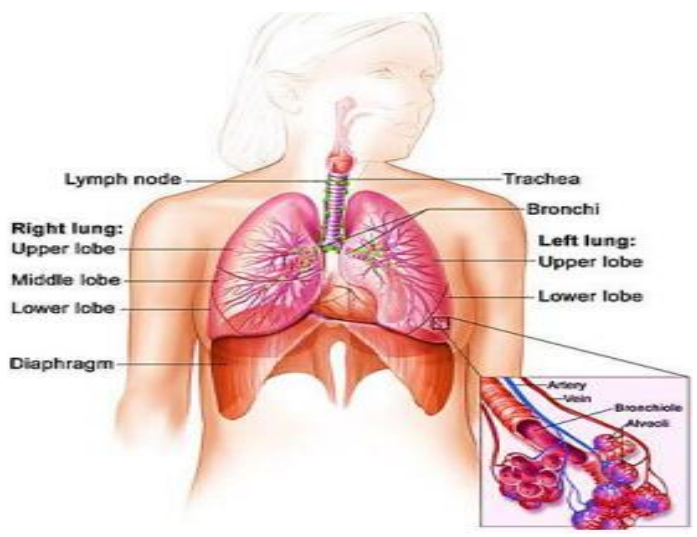

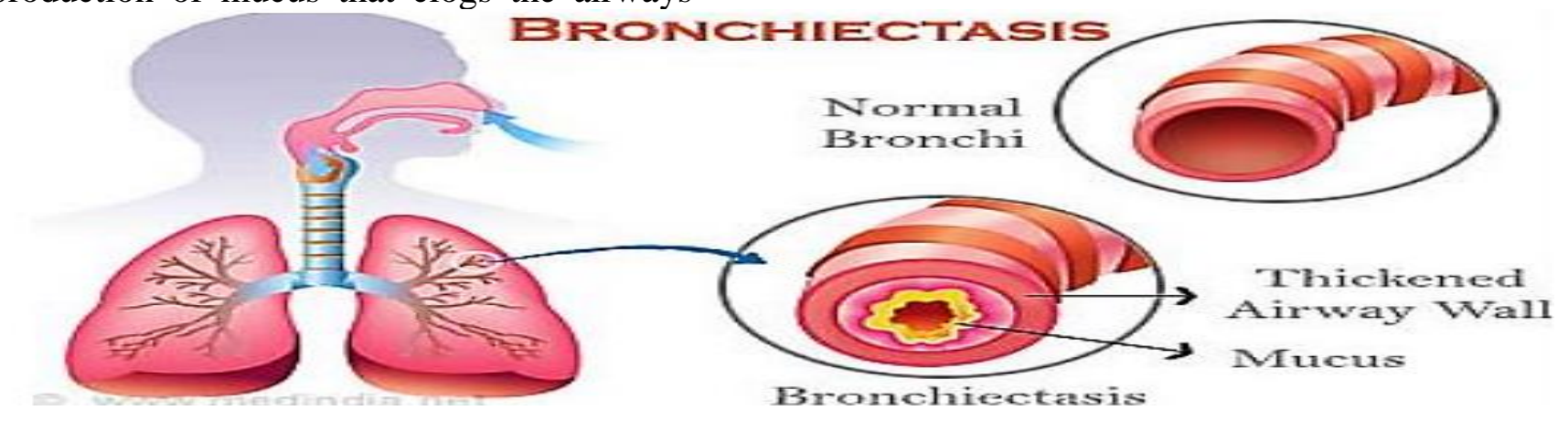

Figure 3: Thickened airway wall and mucus production in bronchiectasis

COPD is usually treated both pharmacologically and non-pharmacologically. Smoking cessation has greatest capacity to influence the natural history of COPD. Pharmacologic therapies include the use of bronchodilators, inhaled corticosteroids, combination of inhaled corticosteroids/bronchodilators, oral corticosteroids, phosphodiestrase-4 inhibitors, methylxanthines, vaccines, alpha-1 antitrypsin augmentation therapy, antibiotics, mucolytic and makes breathing difficult. The mucus is cleared through coughing. Both constant coughing and inflammation can damage the bronchial tubes. The swollen and thickened tubes leave less room for air flow (Figure 2) $[17,18]$. agents, antitussives and vasodilators. Other treatments that can be adopted are rehabilitation, oxygen therapy, ventilatory support, surgical treatments and palliative care/end-of-life care, and hospice care [18]. Bronchial asthma is a heterogeneous pulmonary disorder which is characterized by chronic inflammation of the airways associated with airway hyper responsiveness. This may clue to persistent episodes of cough, breathlessness, chest stiffness and wheezing 
predominantly at night or in early morning. These symptoms may resolve spontaneously or after the use of bronchodilator medication $[19,20]$.

The treatment options for asthma includes inhaled glucocorticosteroids, leukotriene modifiers, long-acting inhaled beta-2-agonists, theophylline, cromones: sodium cromoglycate and nedocromil sodium, long-acting oral beta2-agonists, anti-IgE, systemic glucocorticosteroids, oral anti-allergic compounds etc. [21].

Bronchiectasis (Figure 3) [22] is a permanent lung disease in which the walls of airways in lung are expanded (dilated) and ultimately devastated. Patients with this disease may have chronic sinus infections or inflammation, a chronic cough, and heavy phlegm that often contain blood. Among all ages, it has been estimated that about 25 people per 100,000

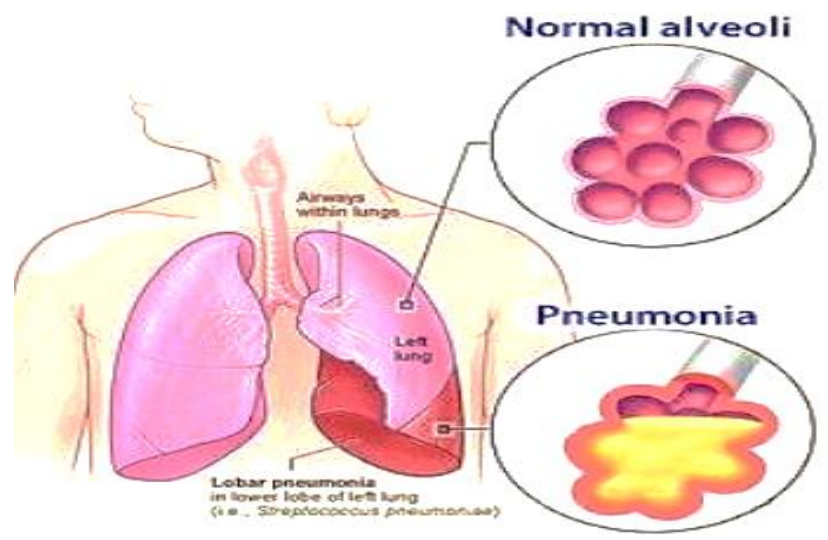

have bronchiectasis, but this number increases to 272 per 100,000 for those over 74 year's old [23].

\section{Risk Factors for Obstructive Lung Diseases and Respiratory Tract Infections}

The most common factor leading to COPD is cigarette smoking, hereditary deficiency of alpha 1-antitrypsin, exposure to tobacco smoke, occupational dust and chemicals. The symptom of COPD ranges from dyspnoea, chronic cough with or without sputum production to poor exercise tolerance. Severity of the symptoms is increased during exacerbations [24,27]. The risk factors of asthma are hereditary as well as environmental. Some among them are genetic predisposition; prenatal factors; exposure to allergens; infections (pneumonia) (Figure 4) [28]; environmental air pollution; tobacco smoke; diet and obesity [29].

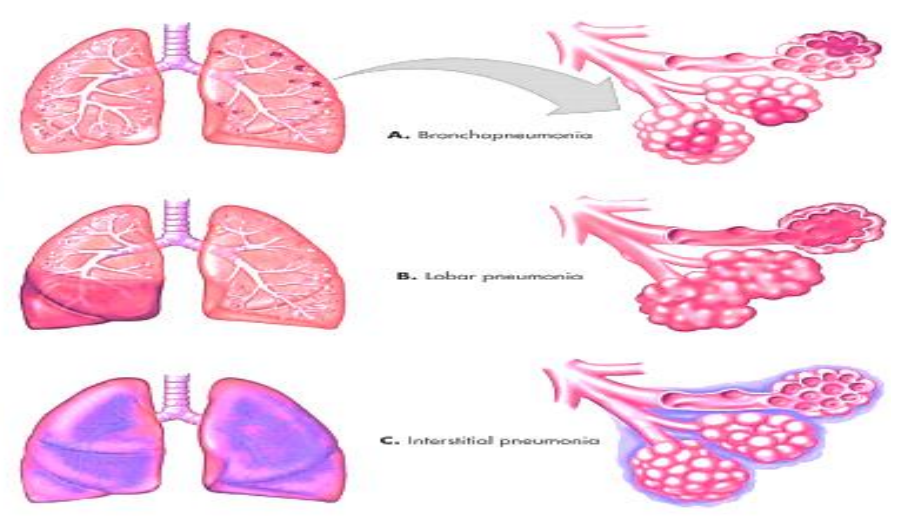

Figure 4: Bronchioles in pneumonia

Transient deterioration of asthma may occur as a result of exposure to risk factors for asthma symptoms, or "triggers," such as exercise, air pollutants, and even certain meteorological conditions e.g., thunderstorms. More persistent worsening is usually due to viral infections of the upper respiratory tract (particularly rhinovirus and respiratory syncytial virus) or allergen exposure which upsurge inflammation in the lower airways (acute or chronic inflammation) that may persist for several days or weeks [23].

\section{Materials and Methodology}

The Ethical clearance for the study was obtained from the Institutional Ethics committee. A Cross Sectional study was carried out in various units such as Intensive Critical
Care Unit (ICCU), Respiratory Intensive Care Unit (RICU), and Medical Intensive Care Unit (MICU), Medical wards (Male and Female) of the department of general medicine/TB and Chest disease department. The essential data for the cross-sectional study was collected from patient case files using a well-designed patient data collection form.

A total of 102 cardiovascular disease patient's files were screened and data was analysed.

\section{Inclusion Criteria}

- Patients of either sex who are aged 18 years and above

- Patients who are diagnosed as suffering from obstructive lung disease and respiratory tract infections (pneumonia 
and acute respiratory infections like common cold, pharyngitis, tonsillitis, bronchitis, otitis media etc. along with comorbidities and who visited the hospital for acute exacerbation of the disease was included using diagnostic criteria such as ICD-10.

- Patients with tobacco smoking.

\section{Exclusion Criteria}

- All pregnant women and lactating mothers, patients in other wards and departments of the hospital.

- Individuals who are not willing to be a part of the study.

- All out patients in Out Patient Department

- Padiatrics

- All patients who has undergone cardiovascular surgery.

- Seriously and mentally ill patients

\section{Source of Data}

Patient files were screened for the demographic information, laboratory investigations, diagnosis and the medication prescribed each day. A suitably designed patient data collection form was used to record all the necessary data. It also includes the present complaints of the patient, past medical history, past medication history, family history, social history (including diet, alcohol/smoking habits, sleep, bowel and bladder, appetite, exercise habit), physical examination, systemic examination etc.

\section{Procedure}

All OLD patients' prescription detail was collected in a specially designed case record form (CRF) for the evaluation of drug prescribing pattern. The medications prescribed for treating OLD were analysed by using GOLD treatment guidelines. The parameters noted were: Name of the drug, Dosage form, Route, Frequency and Duration of administration, Generic/Brand name and the number of drugs received by the individual patients during their hospital stay. The medications prescribed for treating COPD was analysed using GOLD treatment guidelines. The information leaflet containing details of
COPD, use of medications, and life style modifications is prepared after consulting with physicians and pharmacists and issued to patients in their vernacular language.

\section{Statistical Analysis}

After acquiring the details, we have performed various analyses in the collected data. The analysis was based on patient age, gender, social history, $\mathrm{Hb}$ level, $\mathrm{SPO}_{2}$ measurement, drug utilisation pattern etc. Collected information was analysed using Microsoft Office (MS-Word and Excel) 2010. Descriptive data analysis has been performed in the form of percentage of demographic variables and drug therapy and related issues were shown as various tables and graphs for better understanding of data. For the analysis of the results, simple percentage calculations were used to arrive at a conclusion of our study.

\section{Results}

A total number of 102 case sheets of obstructive lung disease and respiratory tract infections patients admitted to MIMS teaching hospital were analysed. Among these 102 patients, majority of the patients were male $\mathrm{n}=65 \quad(63.72 \%)$ and $\mathrm{n}=37 \quad(36.28 \%)$ were females (Figure 5).

Out of 102 patients, 42 were COPD patients comprising of 4 emphysema and 7 chronic bronchitis, 15 were asthma patients, 1 patient with Asthma-COPD overlap syndrome (ACOS), 23 pneumonia patients, 2 Bronchiectasis, 18 COPD patients associated with Co-morbidities, 1 patient with Asthma + Pneumonia (Table 1).

The patients were divided into 7 groups based on their age group (Table 2 and Figure 6).
I. $20-30$ years of age.
II. 31- 40 years of age.
III. 41-50 years of age.
IV. 51-60 years of age.
V. 61-70 years of age.
VI. 71-80 years of age.
VII. 81-90 years of age. 


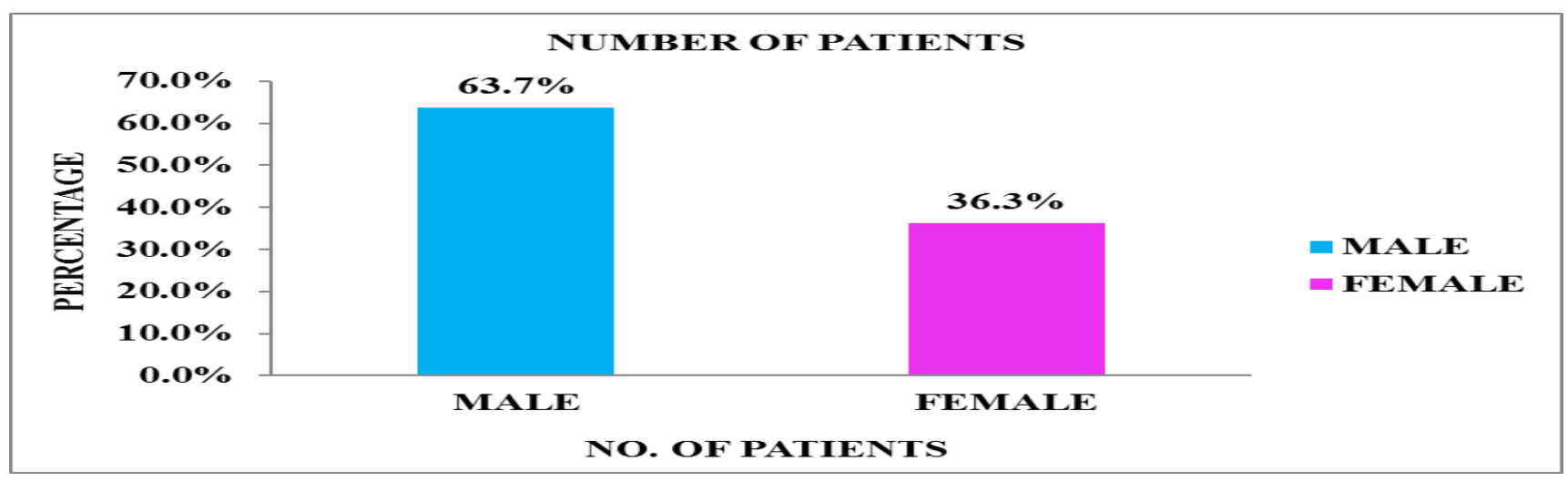

Figure 5: Gender wise distribution of obstructive lung disease and respiratory infection patients

Table 1: Socio-demographic and disease parameters

\begin{tabular}{|c|c|c|}
\hline \multicolumn{3}{|c|}{ Socio-Demographic Parameters } \\
\hline 1 & $\begin{array}{l}\text { Gender } \\
\text { Male } \\
\text { Female }\end{array}$ & $\begin{array}{l}63.72 \% \\
36.28 \%\end{array}$ \\
\hline 2 & $\begin{array}{l}\text { Smoking history } \\
\text { Smokers } \\
\text { Non-smokers } \\
\text { Ex-smokers }\end{array}$ & $\begin{array}{l}48.03 \% \\
11.76 \% \\
40.19 \% \\
\end{array}$ \\
\hline 3 & $\begin{array}{l}\text { Alcoholism } \\
\text { Alcoholic } \\
\text { Non-alcoholic } \\
\text { Ex-alcoholic } \\
\end{array}$ & $\begin{array}{c}53.9 \% \\
28.43 \% \\
17.68 \%\end{array}$ \\
\hline 4 & $\begin{array}{l}\text { Disease condition } \\
\text { COPD } \\
\text { Emphysema } \\
\text { Chronic Bronchitis } \\
\text { Asthma } \\
\text { Asthma-COPD overlap Syndrome } \\
\text { Pneumonia } \\
\text { Bronchiectasis } \\
\text { Asthma + Pneumonia } \\
\text { Acute Exacerbation of COPD + HTN } \\
\text { COPD + Anaemia } \\
\text { COPD + Cor-Pulmonale } \\
\text { Bronchial Asthma + Hypothyroidism } \\
\text { HHD + HTN + COPD + Emphysema + DM } \\
\text { COPD + HTN + IHD + CVA } \\
\text { COPD + Cor-Pulmonale + Respiratory Failure + AF + PAH } \\
\text { Corpulmonale + HTN + DM + Severe PAH + Anaemia } \\
\text { URTI }\end{array}$ & $\begin{array}{l}30.39 \% \\
3.94 \% \\
6.86 \% \\
14.71 \% \\
0.98 \% \\
22.55 \% \\
1.97 \% \\
0.98 \% \\
2.95 \% \\
1.97 \% \\
9.83 \% \\
0.98 \% \\
0.98 \% \\
0.98 \% \\
0.98 \% \\
0.98 \% \\
2.95 \%\end{array}$ \\
\hline
\end{tabular}

\section{Patient Distribution Based on Social History}

Based on the addictive habits such as Smoking and Alcoholism, 102 patients have been divided. 49 patients $(48.03 \%)$ were found to be smokers, 41 patients $(40.19 \%)$ were ex-smokers, and 55 patients (53.9\%) were alcoholics (16\%), 12 patients were nonsmokers $(11.76 \%)$ and 29 were nonalcoholics $(28.43 \%)$ and 18 was ex-alcoholic $(17.68 \%$ ) (Table 3 and Figure 7). 
Table 2: Distribution of patients based on age group and gender

\begin{tabular}{|c|c|c|c|}
\hline Age Group (Year) & Male & Female & Percentage (\%) \\
\hline $20-30$ & 6 & 5 & $10.79 \%$ \\
\hline $31-40$ & 4 & 2 & $5.89 \%$ \\
\hline $41-50$ & 6 & 9 & $14.70 \%$ \\
\hline $51-60$ & 14 & 9 & $22.54 \%$ \\
\hline $61-70$ & 18 & 6 & $23.52 \%$ \\
\hline $71-80$ & 10 & 2 & $11.77 \%$ \\
\hline $81-90$ & 7 & 4 & $10.79 \%$ \\
\hline Total & 65 & 37 & $100 \%$ \\
\hline
\end{tabular}

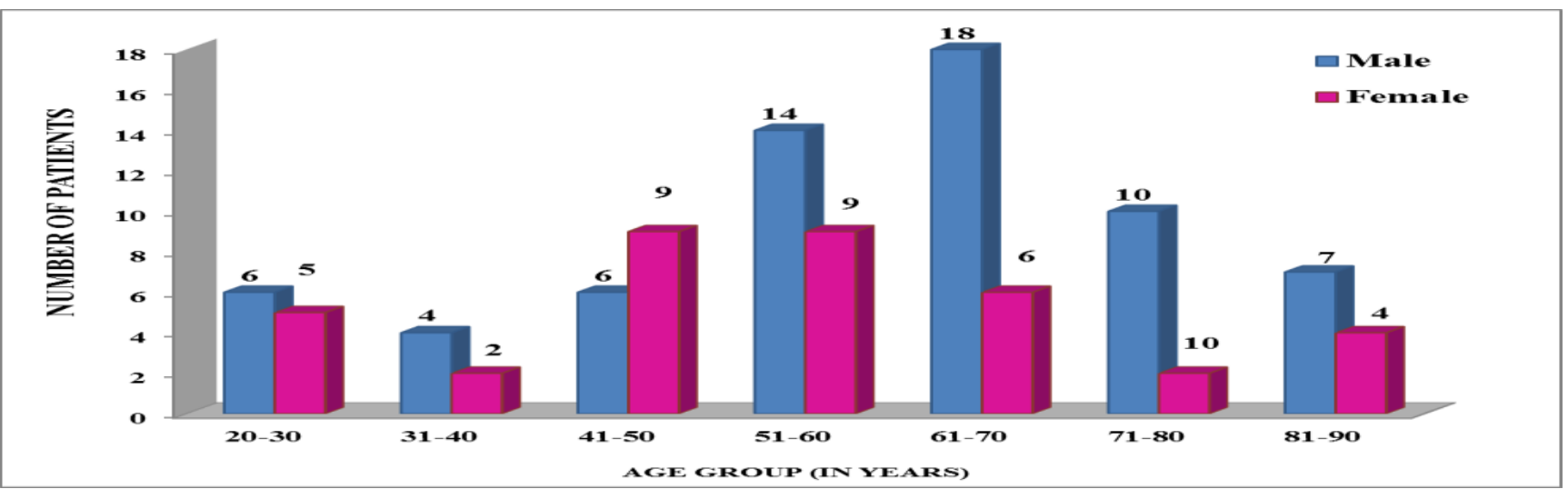

Figure 6: Distribution of patients based on age group and gender

Table 3: Patient distribution based on social history

\begin{tabular}{|c|c|c|c|c|c|}
\hline \multicolumn{3}{|c|}{ Smoking History } & \multicolumn{3}{c|}{ Alcoholism } \\
\hline Smokers & Non-smokers & Ex- smokers & Alcoholic & Non-Alcoholic & Ex-Alcoholic \\
\hline 49 & 12 & 41 & 55 & 29 & 18 \\
$(48.03 \%)$ & $(11.76 \%)$ & $(40.19 \%)$ & $(53.9 \%)$ & $(28.43 \%)$ & $(17.68 \%)$ \\
\hline
\end{tabular}

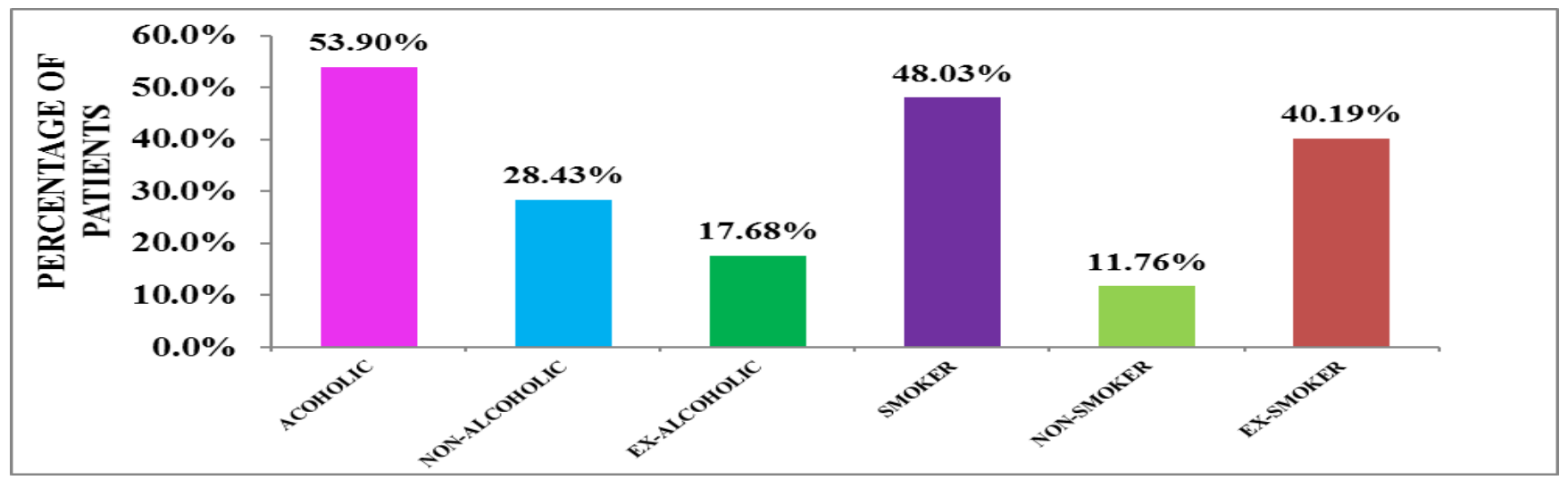

Figure 7: Distribution of Patients Based on Social History 
Table 4: Patient distribution based on $\mathrm{SPO}_{2}$ value

\begin{tabular}{|c|c|c|c|c|}
\hline SPO2 Value & COPD & Asthma & Pneumonia & Total \\
\hline Below 90\% & 22 & 07 & 09 & 38 \\
\hline $90-95 \%$ & 15 & 06 & 06 & 29 \\
\hline Above 95\% & 05 & 02 & 08 & 15 \\
\hline Total & 42 & 11 & 23 & 76 \\
\hline
\end{tabular}

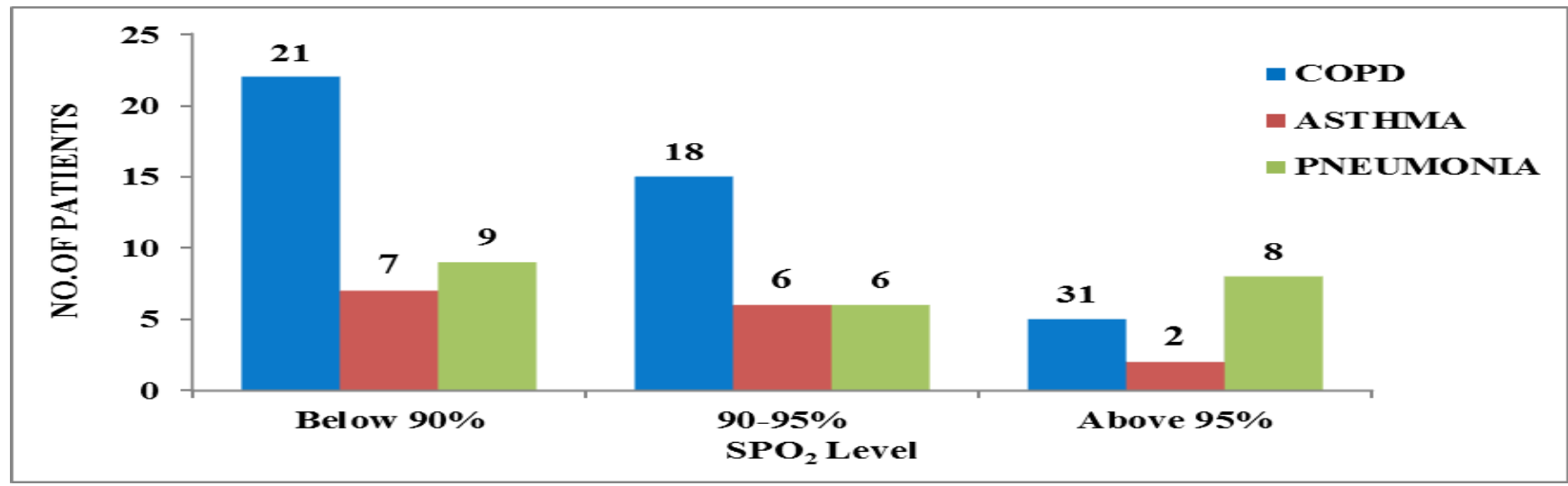

Figure 8: Patient distribution based on $\mathrm{SPO}_{2}$ value

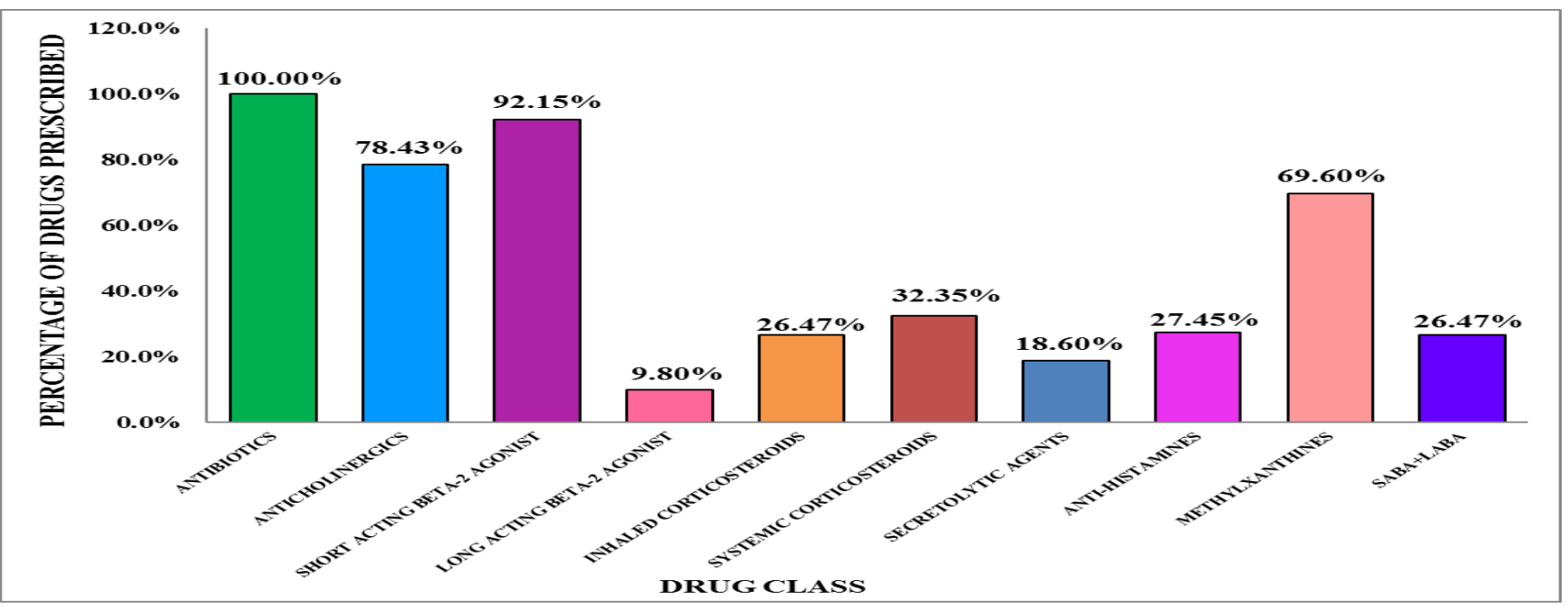

Figure 9: Percentage of drugs prescribed by class

\section{Patient Distribution Based on $\mathrm{SPO}_{2}$ Value}

Out of 125 patients $\mathrm{SPO}_{2}$ measurements were obtained from 38 patients' case sheets and they were categorized into different groups based on their $\mathrm{SPO}_{2}$ values. A total of 33 patients were having $\mathrm{SPO}_{2}$ below $95 \%$ and 05 patients were having $\mathrm{SPO}_{2}$ above $95 \%$ (Table 4 and Figure 8).

\section{Drug Utilization Pattern in Obstructive Lung Diseases and Respiratory Infections}

Among 102 prescriptions, it has been observed that all the prescriptions contained more than 5 drugs. The prescription of more than 5 drugs Rakesh B, et al. Int J Pharm Pharmacol for one patient per prescription may be attributed to the possibility of some patients presenting with acute and chronic exacerbation of COPD and Bronchial Asthma with or without co-morbid conditions, which requires antibiotic and corticosteroid treatment.

Among COPD and Asthma, the class of drugs prescribed mostly were antibiotics (100\%), followed by anti-cholinergics (78.43\%), Short acting beta-2 agonists $(92.15 \%)$, inhaled corticosteroids (26.47\%), Methylxanthines $(69.60 \%)$, systemic corticosteroids $(32.35 \%)$, Long acting beta- 2 agonist $(9.80 \%)$ and secretolytic agents (18.6\%), anti-histamines 
$(27.45 \%)$, combination of short acting beta-2 agonist + Long acting beta-2 agonist (26.47\%) (Figure 9).

\section{Patient Distribution Based on Adjuvant Therapy}

Out of 102 patients apart from main therapy, received adjuvant drugs such as Antacids $(82.35 \%)$, Multivitamins, Minerals and Amino acid preparations $(20.58 \%)$ and NSAIDs (51.96 $\%)$ were prescribed to the patients as adjuvant therapy. Among the antacids Pantoprazole (8.82\%), Ranitidine (73.52\%) and Omeprazole
(5.88\%) were prescribed. Among NSAIDs, Paracetamol (38.23\%) and Diclofenac $(13.72 \%)$ were the relieving pain and fever management and for the management of pneumonia $(36.27 \%)$ of antibiotics Levofloxacin (12.74\%), Pipericillin + Tazobactum (3.92\%), Azithromycin (11.76\%), Amoxicillin (0.98\%), Gentamycin (0.98\%), Amikacin (5.88\%) Erythromycin (0.98\%), Linezolid $(0.98 \%)$ were prescribed which are apart from the antibiotics used in obstructive lung diseases (Figures 10 and 11).

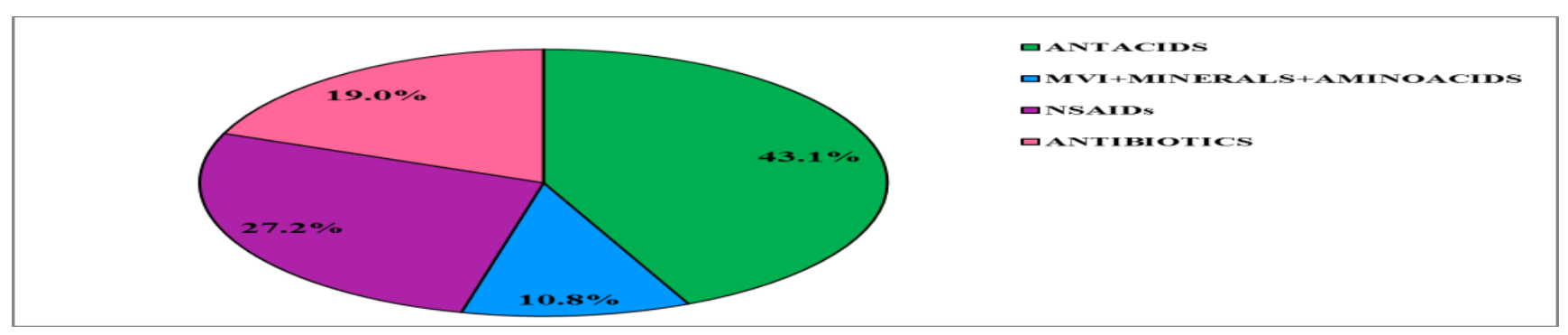

Figure 10: Patient distribution based on adjuvant therapy

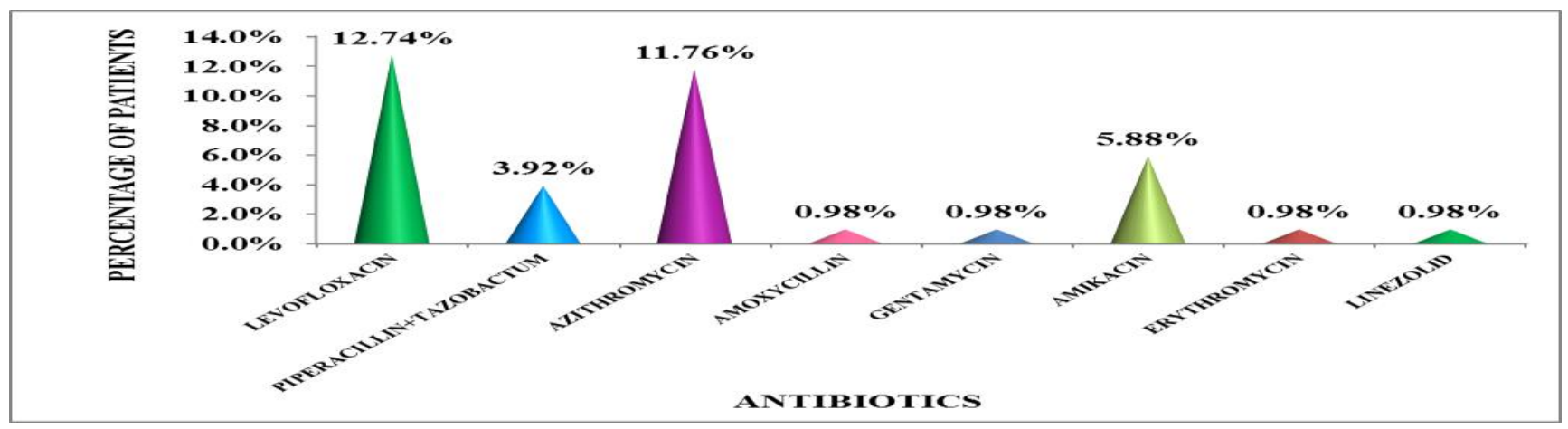

Figure 11: Patient distribution based on antibiotic therapy in pneumonia

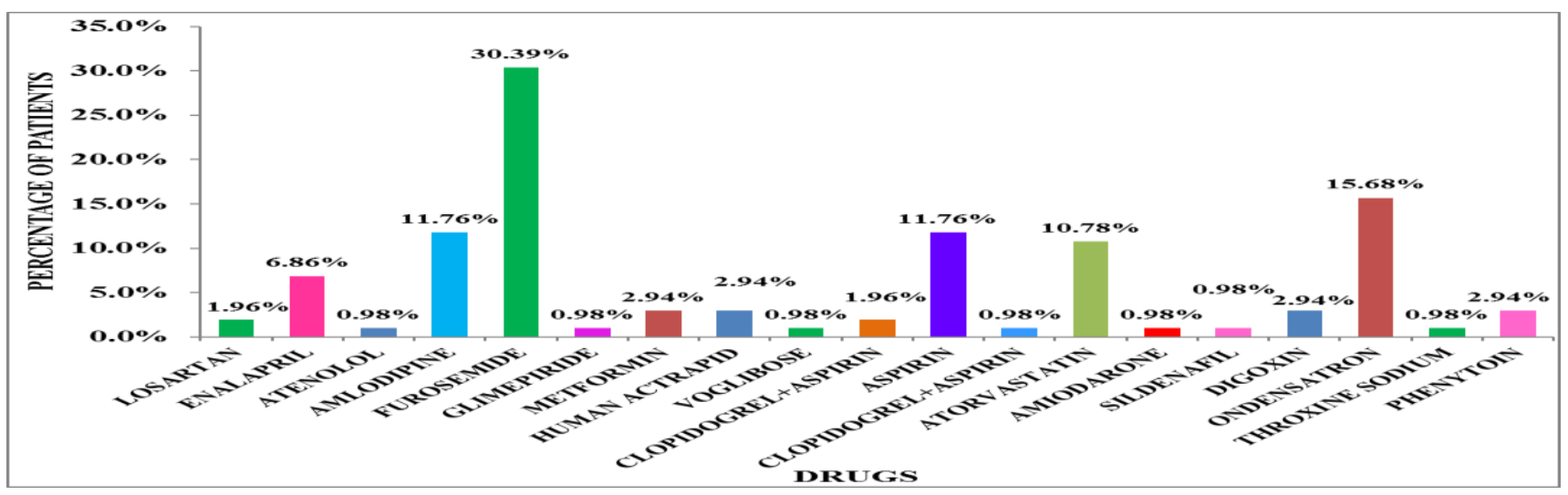

Figure 12: Patient distribution based on miscellaneous drugs

\section{Miscellaneous Drugs}

Out of 102 patients apart from main therapy, Rakesh B, et al. Int J Pharm Pharmacol received miscellaneous drugs for the comorbidities associated with Obstructive Lung Diseases which includes-Losartan (1.96\%), 
Enalapril (6.86\%), Atenolol (0.98\%), Amlodipine (11.76\%) for the management of Hypertension, Furosemide (30.39\%) for the management of Hypertension and CorPulmonale, Glimepiride (0.98\%), Metformin (2.94\%), Human Actrapid (2.94\%) Voglibose $(0.98 \%)$ for Diabetes Mellitus, Clopidogrel + Aspirin (1.96\%), Aspirin (11.76\%), Clopidogrel (0.98\%), Atorvastatin (10.78\%) for Ischaemic Heart Disease, Amiodarone $(0.98 \%)$ for Atrial Fibrillation, Sildenafil (0.98\%) for Pulmonary Arterial Hypertension, Digoxin (2.94\%) for Congestive Cardiac Failure, Ondensatron (15.68\%) for Vomiting/Nausea, Thyroxine sodium (0.98\%) for Hypothyroidism, Eptoin (2.94\%) for Epilepsy (Figure 12).

Table 5: Patient distribution based on monotherapy

\begin{tabular}{|c|c|}
\hline Drug & Percentage \\
\hline Deriphylline & $65.68 \%$ \\
\hline Ceftriaxone & $44.11 \%$ \\
\hline Cefotaxime & 41.17 \\
\hline Budesonide & $26.47 \%$ \\
\hline Hydrocortisone & $20.58 \%$ \\
\hline Chlorpheniramine Maleate & $16.66 \%$ \\
\hline Levofloxacin & $12.74 \%$ \\
\hline Azithromycin & $11.76 \%$ \\
\hline Dexamethasone & $11.76 \%$ \\
\hline Salbutamol & $10.78 \%$ \\
\hline Cetirizine & $10.78 \%$ \\
\hline Amikacin & $5.88 \%$ \\
\hline Aminophylline & $3.92 \%$ \\
\hline Piperacillin+Tazobactum & $3.92 \%$ \\
\hline
\end{tabular}

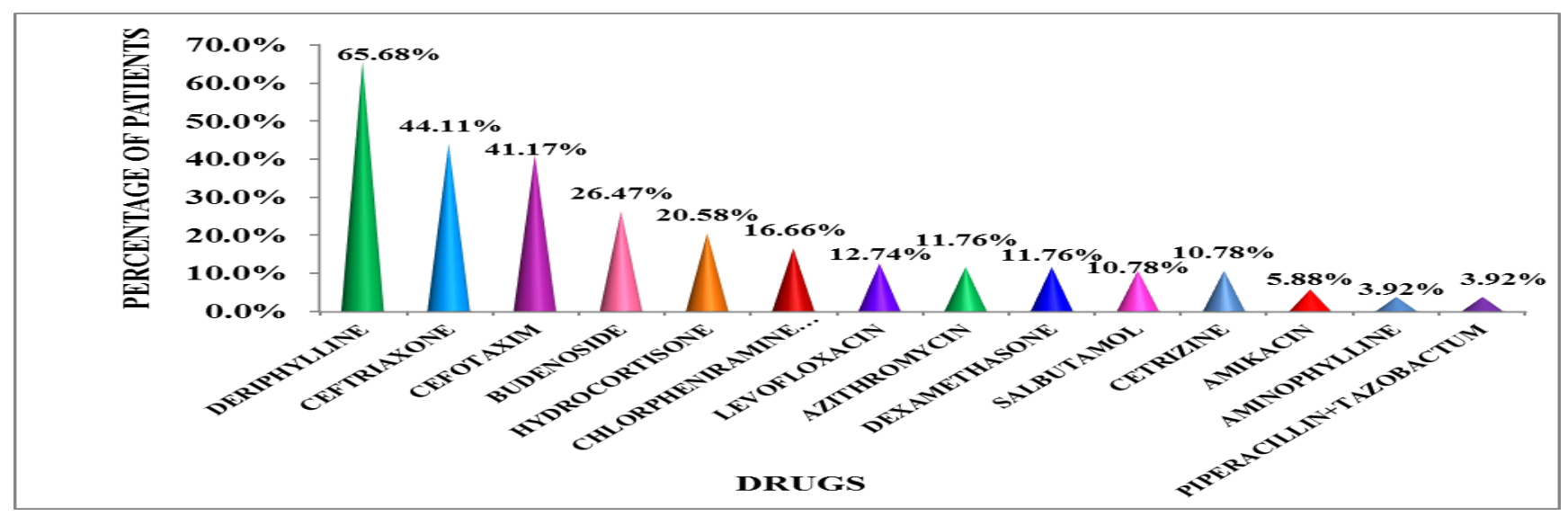

Figure 13: Patient distribution based on monotherapy

\section{Distribution of Patients Based on Monotherapy}

Out of 102 prescriptions, Deriphylline was the drug which was given for majority of patients as single drug (65.68\%), followed by Ceftriaxone (44.11\%), Cefotaxime (41.17\%), Budesonide (26.47\%), Hydrocortisone (20.58\%), Chlorpheniramine Maleate (16.66\%), Levofloxacin (12.74\%), Azithromycin (11.76\%), Dexamethasone $(11.76 \%)$, Salbutamol (10.78\%), Cetirizine
(10.78\%), Amikacin (5.88\%), Aminophylline $(3.92 \%)$, Piperacillin + Tazobactum $(3.92 \%)$ (Table 5 and Figure 13).

\section{Patient Distribution Based on Combination Therapy}

Majority of the patients were prescribed with combination therapy which includesSalbutamol Sulphate + Ipratropium Bromide (12.74\%), Salbutamol Sulphate + Ipratropium Bromide + Budesonide (64.70\%), Ambroxol + 
Salbutamol (0.98\%), Ambroxol + Guaiphenesin + Terbutaline (3.92\%), Bromhexine + Guaiphenesin+ Terbutaline+ Menthol (4.90\%), Ambroxol + Levocetrizine + Monteleukast (2.94\%), Etophylline +
Theophylline (65.68\%), Ambroxol + Guaiphenesin + Levosalbutamol (14.70\%) (Figure 14).

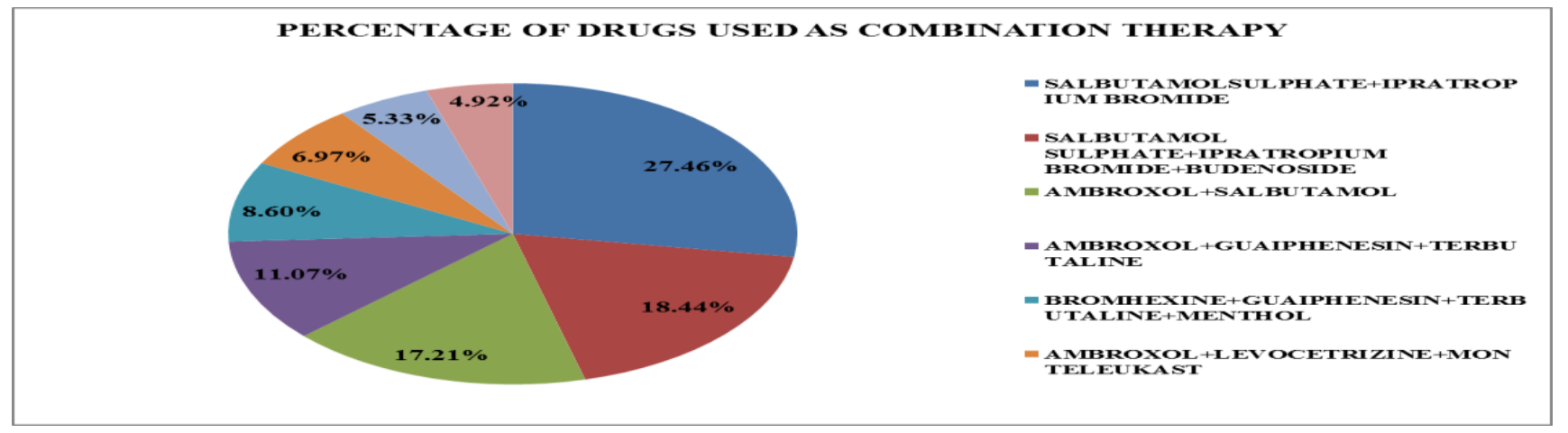

Figure 14: Percentage of drug used as combination therapy

Table 6: Drug interactions

\begin{tabular}{|c|c|c|c|}
\hline Interacting Drugs & Severity & Effect & $\begin{array}{c}\text { No. of Patients } \\
(\%)\end{array}$ \\
\hline Aminophylline + Levofloxacin & Major & $\begin{array}{l}\text { Concurrent use may result } \\
\text { in theophylline toxicity } \\
\text { (nausea, vomiting, } \\
\text { palpitations, and seizures). }\end{array}$ & $7(6.86 \%)$ \\
\hline Aspirin + Diclofenac & Major & $\begin{array}{c}\text { Concurrent use may result } \\
\text { in increased risk of } \\
\text { bleeding. }\end{array}$ & $4(3.92 \%)$ \\
\hline Azithromycin + Levofloxacin & Major & $\begin{array}{l}\text { Concurrent use may result } \\
\text { in increased risk of QT } \\
\text { interval prolongation. }\end{array}$ & $5(4.90 \%)$ \\
\hline Dexamethasone + Diclofenac & Major & $\begin{array}{l}\text { Concurrent use may result } \\
\text { in increased risk of } \\
\text { gastrointestinal ulcer or } \\
\text { bleeding. }\end{array}$ & $3(2.94 \%)$ \\
\hline Azithromycin + Theophylline & Moderate & $\begin{array}{c}\text { Concurrent use may result } \\
\text { in increased serum } \\
\text { theophylline } \\
\text { concentrations. }\end{array}$ & $6(5.88 \%)$ \\
\hline
\end{tabular}

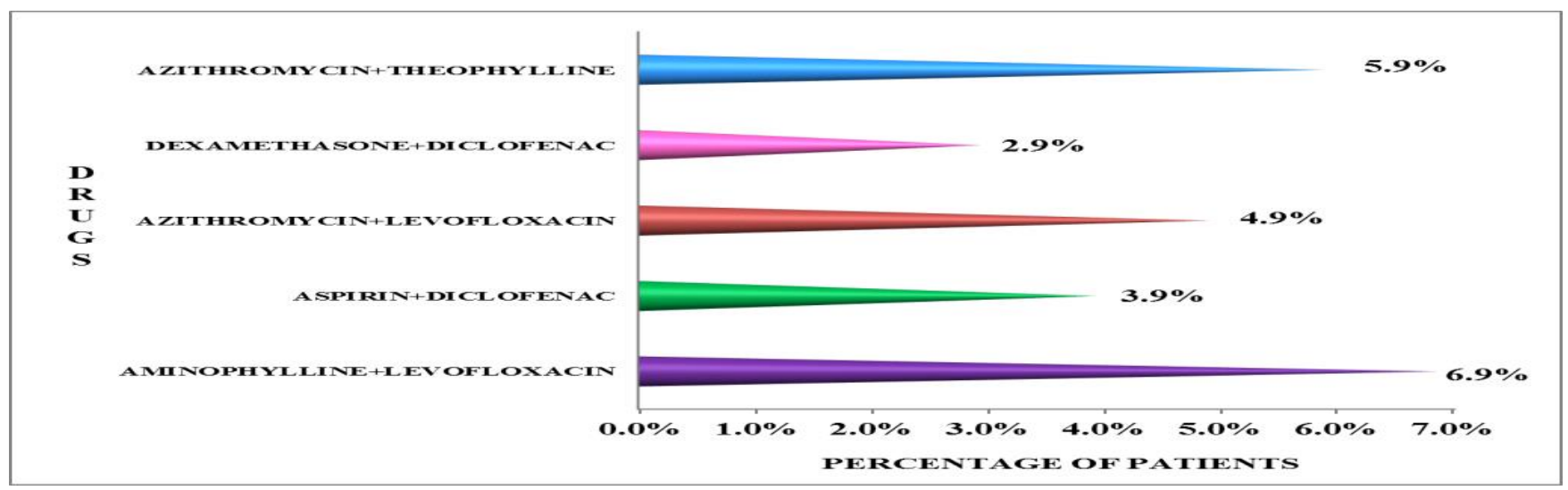

Figure 15: Drug interaction 


\section{Discussion}

Better health care services will have a positive impact on health care system. A lot of population are suffering from these chronic respiratory diseases. Hence it became very essential to spread a thorough awareness among patients in relation to medication and disease itself. So, evaluation of drug utilisation pattern in asthma and COPD will provide a powerful tool in order to find depth of awareness in patients and physician. A prescription based study is considered one of the scientific methods to evaluate the rationality of the prescription. Drug utilization research is an essential part of pharmacoepidemiology as it describes the extent, nature and determinants of drug exposure. Drug use is a complex process. In any country, a large number of socio-cultural factors contribute to the ways drugs [30].

Many studies were conducted to evaluate the value addition of drug therapy management into the patient care in critical care setting but obstructive lung diseases and respiratory infection patient(s) were rarely focused as the chances of readmission in hospitals and number of days of hospitalisation is found more in obstructive lung disease and respiratory infection, so this study aimed to focus on analysis of prevalence, risk factors and drug utilization pattern in the management of obstructive lung disease and respiratory infections in a tertiary care hospital. A drug therapy plan may require discontinuation or addition of a drug as well dosage adjustments and thus requires more complex decisionmaking skills. Determining whether a patient actually requires drug therapy is probably the most intricate problem to identify because the outcomes of the patient's drug therapy depends upon the patient's social history as well pathophysiology and pharmacotherapeutics, which is altered due to disease conditions.

Drug therapy management is an effective mechanism to facilitate assessment of the indications, effectiveness and safety of drug products, especially in patients who are using multiple medications due to concurrent diseases (co-morbidities). Most number of studies have shown that many hospital admissions and readmissions are due to co-morbid conditions, adverse drug events, medication errors or suboptimal prescribing. Study result shows that male patients $(63.72 \%)$ admitted were more compared to female $(36.28 \%)$ and may infer that male are more prone to obstructive lung diseases and respiratory infections compared to female gender. Average age of patients found was between 61-70 years, which indicates that the obstructive lung disease and respiratory infections may be chronic in this age group and is similar to CAGE study (2008) $60 \%$ patient were male [31].

Majority of the cases in this age group includes COPD and COPD with co-morbidities. This increased prevalence is mainly due to the sedentary lifestyle, smoking and alcohol consumption which are potent risk factors for obstructive lung diseases which decreases the oxygenated air supply to the lungs and consequently leads to bronchospasm and in severe cases it leads to death of patient. In our study, the commonest diagnosis was COPD. Lower socioeconomic classes from both urban and rural areas are the sufferers. Industrial pollution is very high in and around Mandya. Up to $25 \%$ of exacerbations in COPD and Asthma are produced by viruses. Major bacterial organisms associated with exacerbations include streptococcus pneumoniae, haemophilus influenzae, mycoplasma pneumoniae or Chlamydia pneumonia.

The patients were categorised on the basis of their Social history, disease conditions. 102 patients were categorised based on their addictive habits such as Smoking and Alcoholism. 49 patients $(48.03 \%)$ were found to be smokers, 41 patients $(40.19 \%)$ were exsmokers, and 55 patients $(53.9 \%)$ were alcoholics (16\%), 12 patients were nonsmokers $(11.76 \%)$ and 29 were non-alcoholics $(28.43 \%)$ and 18 was ex-alcoholic (17.68\%). Globally, COPD by 2020 is expected to rise to the 3 rd position as a cause of death and at 5th position as the cause of loss of disability adjusted life years (DALYs) according to the baseline projections made in the Global Burden of Disease Study (GBDS). The largest increase in the tobacco related mortality is estimated to occur in India, China and other Asian countries [32]. Among 102 prescriptions, it has been seen that all the prescriptions contained more than 5 
drugs. The prescription of more than 3 drugs for one patient may be attributed to the possibility of some patients presenting with acute and chronic exacerbation of obstructive lung diseases with or without co-morbid conditions, which requires antibiotic and corticosteroid treatment. Among COPD and Asthma, the class of drugs prescribed mostly were antibiotics (100\%), followed by anticholinergic (78.43\%), Short acting $\beta-2$ agonists (92.15\%), inhaled corticosteroids $(26.47 \%)$, Methylxanthines $\quad(69.60 \%), \quad$ systemic corticosteroids (32.35\%), Long acting $\beta-2$ agonist $(9.80 \%)$ and secretolytic agents (18.6\%), anti-histamines (27.45\%), combination of short acting $\beta$-2 agonist + Long acting $\beta-2$ agonist (26.47\%).

Pandey et al. in Gorakhpur district of India observed use of multiple drug therapy (81\%) in significant number of patients as compared to single drug therapy (19\%) and use of oral dosage from $(56.3 \%)$ more commonly in comparison to inhalation from in the management of bronchial asthma (33.8). Shimpi et al concluded that $76 \%$ asthma cases were treated with combination therapy and in all therapies methylxanthines were the drug of choice for asthmatic patient's due to their lower cost. The most commonly prescribed combination therapy was budesonide and formoterol followed by ipratropium bromide and salbutamol and salmeterol and fluticasone in their study [33]. Inhaled corticosteroids were used in $15.5 \%$ patients and all of them received budesonide which is almost similar with the previous study by Veettil [34].

Our data shows that prevalence of Drug interactions was more in ICCU, RICU and MICU, which may directly affect the outcome of treatment and hospital stay. Clinical pharmacists play a significant role in critical care units for the better treatment outcomes in critically ill patients by deciding right choice of drug and right doses of medications depending on the patient condition. Medication therapy management becomes more important for patients in critical care units, as they require an extra amount of care and consideration as a consequence of complicated and extensive medication regimens.
Out of 102 cases, 25 (24.50\%) prescriptions are having drug interactions, in which the interactions between the drugs Aminophylline and Levofloxacin were more and are of $6.9 \%$, interactions between Aminophylline and Azithromycin is $5.9 \%$. Even though Drug Interactions were identified, treatment was not stopped as in most of the cases, the drug was absolutely necessary for the patient and the benefits of drug therapy outweighed the risk posed by the Drug Interactions (Figure 13).

\section{Conclusion}

In our study, we observed that the incidence of obstructive lung diseases and respiratory infections was more common in males when compared to females. Majority of the patients were from the age group of 60-69 years. Obstructive Lung diseases are more prominent in smokers when compared to non-smokers. Most of the patients were prescribed with multiple drug therapy out of which inhalation route was the most preferred one. The inhalation route to lungs causes a high local concentration in the lungs with a low systemic delivery, significantly improves the therapeutic effectiveness and minimizes the systemic side effect. Even though Methyl xanthine was the most commonly prescribed class of drug for monotherapy, they could have been avoided due to their adverse effects and instead could have used other safe anti-asthmatics which are available.

Study clearly shows overuse and inappropriate choice of antibiotics for the treatment of acute, uncomplicated RTIs which are mainly due to virus and do not require antibiotic treatment. Results of the study warrant interventional strategies to promote rational use of antibiotics to decrease the overgrowing threat of antibiotic resistance. Minimizing inappropriate antibiotic use is thus the best way to control resistance.

From our study, we found that the total control of obstructive lung diseases was not achieved. The majority of patients had intermittent exacerbations. The pattern of drug utilization is inadequate. GOLD guidelines can be properly followed for prescribing drugs for obstructive lung diseases and can achieve total control. 
Drug therapy should be aimed at treating both the comorbidities and existing conditions rather either alone. Certain drug interactions were also identified in our study, such as Theophylline toxicity, and increased serum concentration of Theophylline. These drug interactions represent that the prescribers are unaware of these reactions. The pharmacist is required to put certain steps in order to improve the awareness among the prescribers and patients as he is a person in close contact with prescribers and patients.

Clinical pharmacists can play a major role prevention and management of obstructive lung diseases that extend beyond the traditional dispensing of medicines. These roles range from provision of educational materials, through screening and monitoring of conditions such as $\mathrm{SPO}_{2}$ to interventions in areas such as smoking cessation, lifestyle modification, medicines management and medication adherence. The presence of clinical pharmacists in medical rounds could assist physicians in optimizing patients' pharmacotherapy. Moreover, clinical pharmacists may reduce adverse effects and medication errors insofar as they contribute significantly to the detection and management of drug related problems, not least in patients with cardiovascular diseases, who have the highest rank in the frequency of medication errors.

\section{Limitations of the Study}

- The external validity of the study may have also been limited by the small sample size, short study duration and follow-up.

- This is the first type of attempt to provide drug utilization evaluation in our setting. Monitoring patients for longer period would reflect more accurate profile of the natural time frame of the medication views. Other chronic diseases can also be managed in a similar manner.

- Establishing the interventions in the form of educational programs can improve the healthy well-being of the patient and decreases the risk of obstructive lung disease complications and also improves the overall drug therapy of the patient.

\section{Future scope of the study}

Rakesh B, et al. Int J Pharm Pharmacol
- This study may be helpful in identifying the new concept of drug therapy management of patients in different disease conditions in critical care and also introduce the new concept of drug therapy management in Karnataka state, India.

- Pharmacoeconomic evaluation studies of medication therapy can be done to assess the burden of obstructive lung diseases and respiratory infections/diseases in the population to avoid unnecessary costs of medication.

- Pharmacoepidemiological studies can be done to study the uses and effects of drugs in well-defined populations.

\section{Conflict of Interest}

There is no conflict of interest in the study.

\section{Financial Support}

Nil

\section{Acknowledgement}

All the authors would like to thank Bharathi College of Pharmacy, Bharathinagara, Mandya, Karnataka, India for continuous support and encouragement throughout this work. Finally, our deepest gratitude goes to the doctors and staff workers of MIMS Teaching Hospital, Mandya, Karnataka, India who helped and allowed us in collecting and gathering data from the hospital.

\section{References}

1. Dipiro JT, Talbert RL, Yee GC, et al. Pharmacotherapy A Pathophysiological approach, $7^{\text {th }}$ edition. 2008; 457-500.

2. Nelson M, Boslev C, Ulrik CS. Clinical characteristics of the asthma-COPD overlap syndrome-a systematic review, Int J COPD 2015; 10: 1443-1454.

3. A Newsletter on obstructive and restrictive lung disease; Reviewed by Melinda Ratini, WebMD 2015.

4. Shimpi RD, Salunkhe PS, Bavaskar SR, et al. Drug utilization evaluation and prescription monitoring in asthmatic patients. Int J Phar Bio Sci 2012; 2: 117122.

5. Sunil S, Gigi A, Hepzhiba P, et al. Drug 
utilization evaluation in chronic obstructive pulmonary disease patients-A prospective study, World J Pharm and Pharm Sci 2015; 5: 1133-1143.

6. Sharma P, Kapoor B. Study of prescribing pattern for rational drug therapy. JK Science 2003; 5: 107-109.

7. http://apps.who.int/medicinedocs/en/d/Js48 82e/8.5.html

8. Unni A, Jayaprakash AK, Yadukrishnan $\mathrm{MC}$, et al. Drug utilization pattern in chronic obstructive pulmonary disease inpatient at a tertiary care hospital. Int $\mathbf{J}$ Phar Pharm Scie 2015; 7: 389-391.

9. Kasper, Fauci, Hauser, et al. Harrison's principles of internal medicine, $19^{\text {th }} \mathrm{Ed}$, Ch 314; 2015: 1700.

10. Dawadi S, Rao BS, Khan GM. Pattern of antimicrobial prescription and its cost analysis in respiratory tract infections. Kathmandu University. J Sci Eng Tech 2005; 1:1-9.

11. Stanton K, Schor G. Nelson text book of pediatrics, Elsevier. 2015; $1: 1107$.

12. Jindal SK, Gupta D, Aggarwal AN, et al. Indian study on epidemiology of asthma, respiratory symptoms and chronic bronchitis. Ind Coun Med Res 2010; 1: 335

13. Institute for Health and Clinical Excellence, chronic obstructive pulmonary disease, management of chronic obstructive pulmonary disease in adults in primary and secondary care. NICE 2010.

14. Joan B, Soriano, Roberto Rodriguez-Roisin. Chronic obstructive pulmonary disease overview epidemiology, risk factors and clinical presentation. Proc Am Thor Soc 2011; 8: 363-367.

15. Vijayan VK. Chronic obstructive pulmonary disease. Ind J Med Res 2013; 137: 251-269.

16. http://diseasespictures.com/emphysema/

17. http://health11.com/health/healthcare/5effective-natural-treatments-chronicbronchitis/

18. http://umm.edu/health/medical/reports/articl es/chronic-obstructive-pulmonary-disease

19. Behera D, Sehgal IS. Bronchial asthmaIssues for the developing world. Ind J Med Res 2015; 141: 380-382.

20. Anuradha A, Kalpana VL, Narsingarao S. Epidemiological study on bronchial asthma. Ind J Alle Asth Immu 2011; 25: 85-89.
21. Global initiative For Asthma, Global Strategy for Asthma Management and Prevention, Revised in 2006, www.ginasthma.org.

22. 22.http://www.medindia.net/patients/patient info/bronchiectasis.htm

23. https://thoracic.org/patients/patientresources/chapter-4-brochiectasis.

24. WHO. Burden of COPD. http://www.who.int/respiratory/copd/burde $\mathrm{n} / \mathrm{en} /$ (accessed)

25. Global strategy for the diagnosis, management, prevention of chronic obstructive pulmonary disease updated 2010. http:// www.goldcopd.org.

26. Lindberg A, Jonsson AC, Rönmark E, et al. Prevalence of chronic obstructive pulmonary disease according to BTS, ERS, GOLD and ATS criteria in relation to doctor's diagnosis, symptoms, age, gender, and smoking habits. Resp 2005; 72: 471479.

27. Viegi G, Pistelli F, Sherrill DL, et al. Definition, Epidemiology and Natural History of COPD. Eur Respir J 2007; 30: 993-1013.

28. www.tabletsmanual.com/wiki/read/pneumo nia

29. Senior RM, Atkinson JJ. Chronic obstructive pulmonary disease: Epidemiology, pathophysiology, and pathogenesis. Fishman's Pulmonary Disease and Disorders Printed in China. $4^{\text {th }}$ ed. China: The McGraw-Hill press; 707-26.

30. Sachdeva PD, Patel BG. Drug utilization studies- scope and future perspectives. IJPBR 2010; 1: 11 -17.

31. Hurd S. The impact of COPD in lung health worldwide: Epidemiology and incidence. Chest 2000; 117: 1S-4S.

32. Bourbeau J, Sebaldt RJ, Day A, et al. Practice patterns in the management of chronic obstructive pulmonary disease in primary practice: The CAGE study. Can Respir J 2008; 15: 13-19.

33. Thamby SA, Juling P, Wan Xim BT, et al. Retrospective studies on drug utilisation patterns of asthmatics in a government hospital in Kedan, Malaysia. Int Curr Pharm J 2012; 1: 353-360.

34. 34. Veettil SK, Rajiah K, Kumar S. Study of Drug Utilization Pattern for Acute Exacerbation of Chronic Obstructive 
Pulmonary Disease in Patients Attending a Fam Med Prim Care 2014; 3: 250-254.

Government Hospital in Kerala, India. J

This manuscript was peer-reviewed

\section{Mode of Review: Single-blinded}

\section{Editor: Dr. V. B. Kadam}

International Journal of Pharmaceutics and Pharmacology is an open access, peer reviewed journal published by Edwiser International.

Submit your valuable manuscript at-

editor.ijpp@edwiserinternational.com

submit.manuscript@edwiserinternational.com

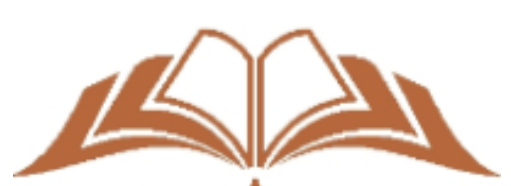

EDW $\mathrm{SER}$
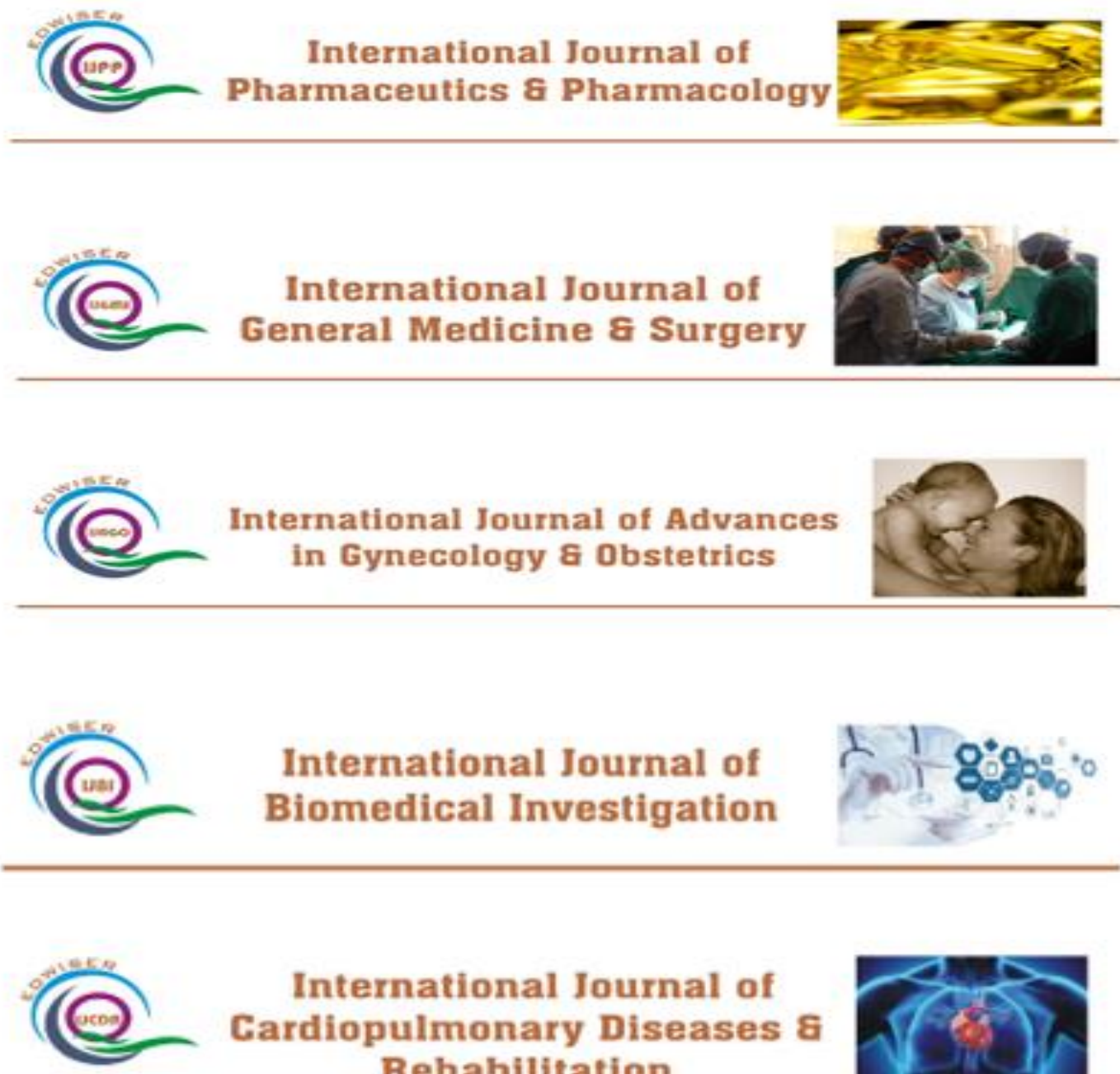

\section{International Journal of Cardiopulmonary Diseases \& Rehabilitation}

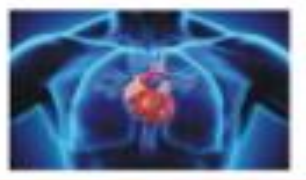

